\title{
ENHANCED VENTILATORY AND HEART RATE RESPONSIVENESS TO HYPOXIA DURING MODERATE EXERCISE IN MAN
}

\author{
Yoshio Ohyabu, Midori Sato and Yoshiyuki Honda
}

\begin{abstract}
One male and eleven female subjects were examined in order to compare their ventilatory and heart rate responsiveness to hypoxia at rest and during moderate exercise $(60 \mathrm{~W})$.

1) The slopes of the ventilatory response curve to hypoxia ( $A v E$ ) were $306.5 \pm 229.5$ and $1,082.9 \pm 928.3 l \cdot \mathrm{min}^{-1} \cdot \mathrm{mmHg}$ at rest and during exercise, respectively. Significant difference $(p<0.05)$ between the two groups was found.

2) The slopes of the hypoxia-heart rate response curve $\left(A_{\mathrm{HR}}\right)$ were $704.9 \pm 477.3$ and $1,165.5 \pm 587.8$ beats $\cdot \mathrm{min}^{-1} \cdot \mathrm{mmHg}$ at rest and during exercise, respectively. The latter was significantly greater than the former $(p<0.05)$.

3) A significant relationship between $A_{v E}$ and $A_{H R}$ was observed $(p<0.05)$.

4) The relationship between $\Delta \dot{\mathrm{V}}_{\mathrm{E}_{50}}$ and $\Delta \mathrm{HR}_{50}$, the increments of ventilation and heart rate from room-air to end-tidal $\mathrm{P}_{2} 50 \mathrm{mmHg}$, was also significant $(\mathrm{p}<0.01$ ).

These results indicate that hypoxic ventilatory and heart rate responsiveness during exercise is significantly greater than at rest, and point to the highly synergistic nature of the relationship between respiratory and cardiac regulations.
\end{abstract}

(Jpn. J. Phys. Fitness Sports Med. 1988, $37: 93 \sim 99$ )

key words : Ventilation, Heart Rate, Hypoxia, Exercise, Man.

\section{Introduction}

Although many hypotheses have been proposed regarding the mechanism of hyperpnea during exercise, general agreement has as yet to be achieved. A number of studies indicated that the mechanism of exercise hyperpnea is related to the chemical control of breathing. Asmussen and Nielsen ${ }^{11}$ has found that exercise hyperpnea decreased by $\mathrm{O}_{2}$ inhalation. Honda et al. $^{101}$ showed the decreased exercise hyperpnea in patients with bilateral carotid chemoreceptor resections. Furthermore, Weil et al. ${ }^{28)}$ and Martin et al. ${ }^{17)}$ demonstrated an augmentation of ventilatory sensitivity to hypoxia during moderate exercise in normal humans. These results suggest that the contribution of peripheral chemoreceptors is greater during exercise than at rest.

On the other hand, Eldridge et al. ${ }^{8)}$ observed that respiratory and circulatory activities were simultaneously augmented by electrical and chemical stimulations of a specific region in the hypothalamus, and locomotion was thereby elicited in cats.

The present investigation was undertaken to examine 1) if such augmented hypoxic responsiveness can be seen in both ventilatory and heart rate activities and 2) whether or not both ventilatory and heart rate responses are quantitatively well related to each other.

\section{Materials and Methods}

\section{A. Subjects}

The physical characteristics of 1 male and 11 female subjects are listed in Table 1 . A brief explanation of the proposed study was given to each subject and consent was obtained.

\section{B. Experimental procedure}

Fig. 1 shows the experimental set-up used in

千葉大学医学部第二生理学教室 Department of Physiology, School of Medicine, Inohana, Chiba, 280 Japan 千280 千葉市いのはな1-8-1 
Table 1. Physical characteristics of the subjects.

\begin{tabular}{lc}
\hline $\mathrm{n}$ & 12 (one male and 11 females) \\
Age $(\mathrm{yrs})$ & $20.6 \pm 5.5$ \\
Body weight $(\mathrm{kg})$ & $58.8 \pm 7.2$ \\
Body height $(\mathrm{cm})$ & $162.2 \pm 3.9$ \\
$\dot{\mathrm{V}}_{\mathrm{O}_{2}}\left(\mathrm{~m} l \cdot \mathrm{min}^{-1}\right)$ & \\
Rest & $307 \pm 39$ \\
Exercise $(60 \mathrm{~W})$ & $1,099 \pm 160$ \\
\hline
\end{tabular}

Values are mean $\pm \mathrm{SD}$.

$\dot{V}_{\mathrm{O}_{2}}$, Oxygen uptake

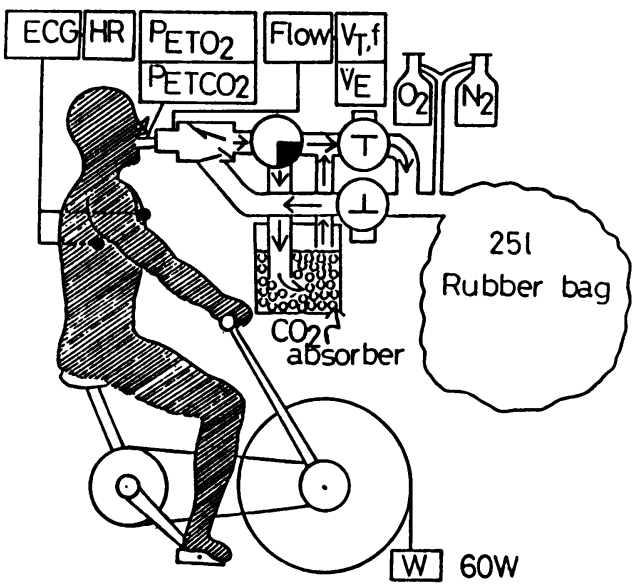

Fig. 1. A schematic drawing of the experimental set-up.

these studies.

The subjects, holding a mouth-piece in place, breathed room air at first, then started rebreathing into a bag which was filled with room air. By adjusting the amount of $\mathrm{CO}_{2}$ absorbed by a $\mathrm{CO}_{2}$ absorber in the by-pass circuit, end-tidal $\mathrm{P}_{\mathrm{CO}_{2}}\left(\mathrm{P}_{\mathrm{ETCO}}\right)$ was kept at normocapnia both at rest and in exercise. After bicycle exercise with room air breathing for $5 \mathrm{~min}$, a progressive hypoxia test was conducted. The work rate during exercise was 1.0 $\mathrm{kp}$ at $60 \mathrm{rpm}$. Then, while maintaining the end-tidal $\mathrm{P}_{\mathrm{CO}_{2}}$ constant, end-tidal $\mathrm{P}_{\mathrm{O}_{2}}\left(\mathrm{P}_{\mathrm{ETO} 2}\right)$ was progressively lowered by rebreathing room-air into the bag. The rebreathing was terminated when $\mathrm{P}_{\mathrm{ETO} 2}$ decreased to $40 \mathrm{mmHg}$ at rest and $50 \mathrm{mmHg}$ during exercise, respec. tively.

A probe with a hot wire respiratory flowmeter (Minato Medical Science CO. Ltd., Tokyo, Japan) inserted between the rebreathing bag and the mouth-piece was used to detect the breath-by-breath respiratory flow, which was then integrated to tidal volume. ECG was recorded only on the chest (SAN-EI Cardiosuper $2 \mathrm{E} 31 \mathrm{~A}$ ). The average heart rate was then obtained from every $8 \mathrm{R}-\mathrm{R}$ interval.

The oxygen consumption $\left(\dot{\mathrm{V}}_{\mathrm{O}_{2}}\right)$ at rest and in exercise during room air breathing was determined by collecting expired air for 5 and $2 \mathrm{~min}$, respectively. The amount of collected air and its $\mathrm{O}_{2}$ and $\mathrm{CO}_{2}$ concentrations were measured by a dry gasometer, and $\mathrm{O}_{2}$ and $\mathrm{CO}_{2}$ analyzer (SAN-EI Expired Gas Monitor $1 \mathrm{H} 21$, Tokyo), respectively.

\section{Data analysis}

An example of the experimental record is illustrated in Fig. 2. While maintaining $\mathrm{P}_{\text {ETCO2 }}$ constant, $\mathrm{P}_{\mathrm{ETO} 2}$ decreased progressively. In Fig. 3 both $\dot{\mathrm{V}}_{\mathrm{E}}$ and HR were plotted against $\mathrm{P}_{\mathrm{ETO2}}$. Both responses were analyzed by a modified hyperbolic equation(Weil et al. ${ }^{28)}$ ), which Lloyd and Cunningham ${ }^{16)}$ originally used to evaluate ventilatory responses to steady state hypoxia.

$$
\dot{\mathrm{V}}_{\mathrm{E}}=\mathrm{A}_{\mathrm{VE}} /\left(\mathrm{P}_{\mathrm{ETO} \mathrm{O}_{2}}-\mathrm{C}_{\mathrm{VE}}\right)+\dot{\mathrm{V}}_{\mathrm{O}}
$$

The same hyperbola equation was also applied to the heart rate response in our previous cummunication (Ohyabu et al. ${ }^{23)}$ ) as :

$\mathrm{HR}=\mathrm{A}_{\mathrm{HR}} /\left(\mathrm{P}_{\mathrm{ETO} 2}-\mathrm{C}_{\mathrm{HR}}\right)+\mathrm{HR}_{\mathrm{O}}$, where $\dot{V}_{E}$ and $H R$ are minute ventilations and heart rate, $\dot{\mathrm{V}}_{0}$ and $\mathrm{HR}_{0}$ are horizontal asymptotes in ventilation and in heart rate for infinite $P_{E T 02}, A_{V E}$ and $A_{H R}$ are the slope constants of the hyperbola expressing the degree of hypoxic sensitivity of the subjects, and $\mathrm{C}_{\mathrm{VE}}$ and $\mathrm{C}_{\mathrm{HR}}$ are vertical asymptotes in $\mathrm{P}_{\mathrm{ETO} 2}$ for 

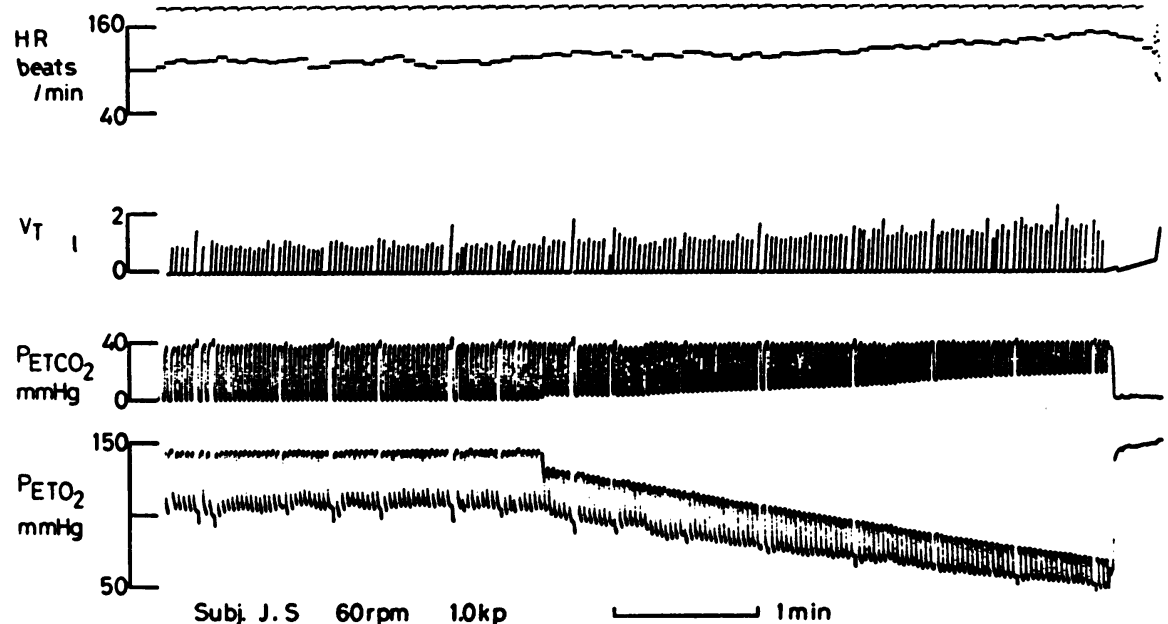

Fig. 2. An example of ventilatory and heart rate responses to progressive isocapnic hypoxia during exercise.

Ventilatory response Heart rate response

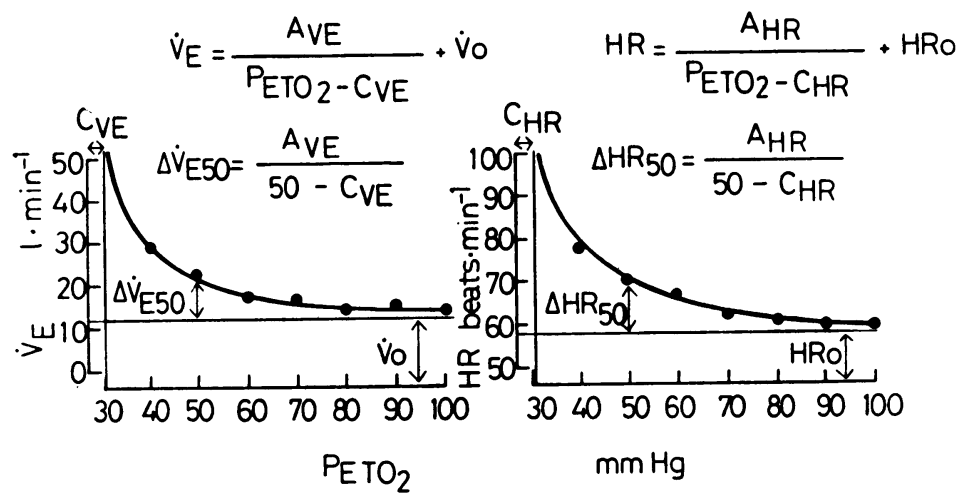

Fig. 3. Ventilatory and heart rate responses are plotted against end-tidal $\mathrm{Po}_{2}\left(\mathrm{PETO}_{2}\right)$. Data were obtained from subj. A. W. Both responses are shown to be adequately expressed by the hyperbola equation described in the figure.

infinite $\dot{V}_{E}$ and $H R$.

To obtain the above three parameters in the equation, $\mathrm{C}_{\mathrm{VE}}$ and $\mathrm{C}_{\mathrm{HR}}$ were first determined by a curve-fitting procedure using a microcomputer (NEC 9800), i. e., for seeking the $\mathrm{C}_{\mathrm{VE}}$ and $C_{H R}$ values which gave the best correlation coefficients between $\dot{\mathrm{V}}_{\mathrm{E}}$ and $1 /\left(\mathrm{P}_{\mathrm{ETO} 2}-\mathrm{C}_{\mathrm{VE}}\right)$ and $\mathrm{HR}$ and $1 /\left(\mathrm{P}_{\mathrm{ETO}_{2}}-\mathrm{C}_{\mathrm{HR}}\right)$.

Then, from the linear regression between $\dot{\mathrm{V}}_{E}$ and $1 /\left(\mathrm{P}_{\mathrm{ETO} 2}-\mathrm{C}_{\mathrm{VE}}\right)$ or HR and $1 /\left(\mathrm{P}_{\mathrm{ETO} 2}-\mathrm{C}_{\mathrm{HR}}\right)$,
$\dot{\mathrm{V}}_{\mathrm{O}}$ and $\mathrm{A}_{\mathrm{VE}}$ or $\mathrm{HR}_{0}$ and $\mathrm{A}_{\mathrm{H} R}$ were determined as the intercept at the ordinate and the slope of the regression line, respectively (Fig. 3 ).

The absolute magnitudes of hypoxic response in ventilation and heart rate at $\mathrm{P}_{\mathrm{ETO} 2} 50 \mathrm{mmHg}$ were also determined as $\Delta \dot{\mathrm{V}}_{\mathbf{E}_{30}}$ and $\Delta \mathrm{HR}_{\mathbf{3 0}}$, respectively, which were calculated as follows:

$$
\begin{aligned}
& \Delta \dot{\mathrm{V}}_{\mathrm{E} 50}=\mathrm{A}_{\mathrm{VE}} /\left(50-\mathrm{C}_{\mathrm{VE}}\right), \\
& \Delta \mathrm{HR}_{50}=\mathrm{A}_{\mathrm{VE}} /\left(50-\mathrm{C}_{\mathrm{HR}}\right) .
\end{aligned}
$$




\section{Results}

\section{A. Ventilatory and heart arte responses}

As seen in Table 2, the slopes of the ventilatory response to hypoxia $\left(\mathrm{A}_{\mathrm{VE}}\right)$ were $306.5 \pm$ 229.1 and $1,082.9 \pm 928.3 l \cdot \mathrm{min}^{-1} \cdot \mathrm{mmHg}$ at rest and at exercise, respectively. Avr of exercise was significantly greater than that of rest $(p<$ $0.05)$. The horizontal asymptotes of the ventilatory response to hypoxia $\left(\dot{\mathrm{V}}_{0}\right)$ were $4.7 \pm 2.9$ and $16.2 \pm 9.0 l \cdot \mathrm{min}^{-1}$ at rest and at exercise, respectively, with the latter being significantly higher $(\mathrm{p}<0.001)$.

Table 2, Ventilatory and heart rate responses to hypoxia

\begin{tabular}{|c|c|c|}
\hline & Rest & Exercise \\
\hline $\operatorname{AvE}_{E}\left(1 \cdot \min ^{-1} \cdot \mathrm{mmHg}\right)$ & $306.5 \pm 229.1$ & $1,082.9 \pm 928.3^{*}$ \\
\hline $\mathrm{C}_{\mathrm{VE}}(\mathrm{mmHg})$ & $13.9 \pm 12.9$ & $21.9 \pm 10.8$ \\
\hline$\dot{\mathrm{V}}_{0}\left(1 \cdot \min ^{-1}\right)$ & $4.7 \pm 2.9$ & $16.2 \pm 9.0^{* *}$ \\
\hline$\Delta \dot{\mathrm{V}}_{\mathrm{E}_{50}}\left(1 \cdot \mathrm{min}^{-1}\right)$ & $8.9 \pm 5.6$ & $38.4 \pm 22.1^{*}$ \\
\hline $\mathrm{A}_{\mathrm{HR}}\left(\right.$ beats $\bullet \mathrm{min}^{-1} \cdot \mathrm{mmHg}$ ) & $704.9 \pm 477.3$ & $1,165.5 \pm 587.8^{*}$ \\
\hline $\mathrm{C}_{\mathrm{HR}}(\mathrm{mmHg})$ & $17.5 \pm 14.6$ & $21.5 \pm 10.0$ \\
\hline $\mathrm{HR}_{0}\left(\right.$ beats $\left.\cdot \min ^{-1}\right)$ & $72.5 \pm 12.7$ & $112.1 \pm 12.9 * *$ \\
\hline$\Delta \mathrm{HR}_{30}\left(\right.$ beats $\left.\bullet \mathrm{min}^{-1}\right)$ & $18.5 \pm 9.0$ & $39.9 \pm 14.3^{*}$ \\
\hline
\end{tabular}

Values are mean $\pm \mathrm{SD}$.

* and ${ }^{* *}$ : The differences compared to the values at rest are significant at the 5 and $0.1 \%$ levels, respectively. Paired $t$ test was conducted.

The slopes of the heart rate response to hypoxia $\left(\mathrm{A}_{\mathrm{HR}}\right)$ were $704.9 \pm 477.3$ and $1,165.5 \pm$ 587.8 beats $\cdot \mathrm{min}^{-1} \cdot \mathrm{mmHg}$ at rest and at exercise, respectively. $A_{H R}$ of the exercise was significantly greater than that of rest $(p<$ 0.05). Furthermore, the horizontal asymptotes of the heart rate response to hypoxia $\left(H_{0}\right)$ were $72.5 \pm 12.7$ and $112.1 \pm 12.9$ beats $\cdot \mathrm{min}^{-1}$. $\mathrm{mmHg}$ at rest and at exercise, respectively, with the latter being significantly greater $(\mathrm{p}<$ 0.001 ).

\section{B. Relatioship between ventilatory and heart rate responses}

Fig. 4 shows the relationship between $A_{V E}$ and $A_{\mathrm{HR}}$. Significant correlation was observed. Fig. 5 shows the relationship between $\Delta \dot{\mathrm{V}}_{\mathrm{E}_{50}}$ and $\Delta \mathrm{HR}_{50}$, again with a significant correlation.

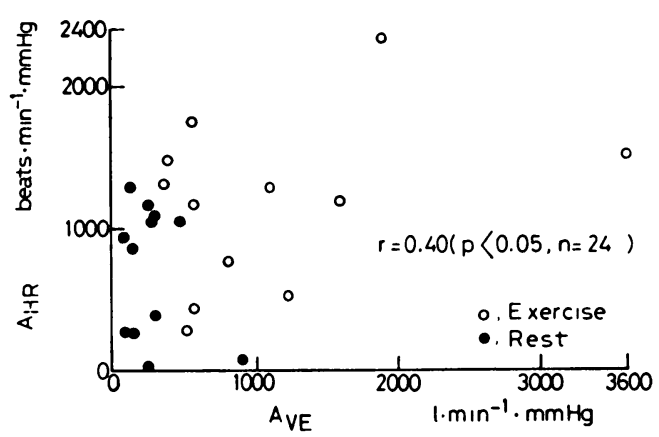

Fig. 4. The relationship between hypoxic ventilatory and heart rate sensitivities (AvE vs $\left.A_{H R}\right)$. A significant correlation was seen.

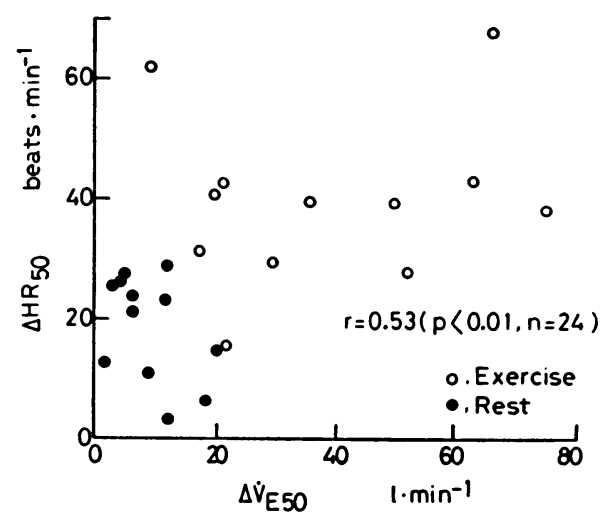

Fig. 5. The relationship between $\Delta \dot{\mathrm{V}}_{\mathrm{E}_{50}}$ and $\Delta \mathrm{HR}_{50}$. The relationship was significant. $\Delta \dot{\mathrm{V}}_{\mathrm{B}_{50}}$ : The absolute magnitude of hypoxic response in ventilation at $\mathrm{P}_{\mathrm{ETO}_{2}} 50 \mathrm{mmHg} ; \Delta \mathrm{HR}_{50}$ : The absolute magnitude of hypoxic response in heart rate at $\mathrm{PETO}_{2} 50 \mathrm{mmHg}$.

\section{Discussion}

The present study demonstrated that both ventilatory and heart rate responsiveness to hypoxia were enhanced during exercise. In 
addition, the extent of both enhancements showed a significant correlation with each other.

Numerous factors have been proposed as affecting exercise hyperpnea : 1) The reflexes from the limbs (Comroe and Schmidt), Kao et al. ${ }^{11}$, Dixon et $a 1 .{ }^{6}$, MacCloskey and Mitchell $\left.{ }^{18}\right)$, Increased excitement of the respiratory center (Krogh et al. ${ }^{12)}$, Eldridge et al. ${ }^{78}$ ), 3)Augmented peripheral chemosensitivity (Weil et al. ${ }^{28)}$, Martin et al. ${ }^{17)}$, Honda et al. $\left.{ }^{10)}\right)$, 4)Augmented central chemosensitivity (Cunningham et al. ${ }^{5}$, Weil et al. ${ }^{28)}$, Spode and Schläfke ${ }^{25)}$, Miyamura et al. ${ }^{21)}$ ), 5)Hyperthermia (Natalino et al. ${ }^{22)}$, Petersen et al. ${ }^{24)}$ ), 6) Hyperpnea secondary to cardiac output increase (Wasserman et al. ${ }^{26)}$, Miyamoto et $a .^{20)}$ ), and 7)Metabolic acidosis (Wasserman ${ }^{27)}$ ).

Of the various findings of these studies, those of Weil et al. ${ }^{28}$, Martin et al. ${ }^{17)}$ are in close agreement with the present data. The increased $A_{V E}$ and $\dot{V}_{0}$ as represented in Table 2 are very similarly to their data.

A number of investigators have proposed possible mechanisms to explain the involvement of peripheral chemoreceptors in exercise hyperpnea. Yamamoto ${ }^{29}$ ) pointed out that increased $\mathrm{CO}_{2}$ production by exercise will make greater arterial $\mathrm{P}_{\mathrm{CO}_{2}}$ oscillation in synchronization with the respiratory cycle, and that this would stimulate ventilation even with the mean arterial $\mathrm{P}_{\mathrm{CO}_{2}}$ remaining unchanged. In a recent review, Linton et al. ${ }^{14,15)}$ and Band et al. ${ }^{2}$ reported that arterial plasma potassium rose rapidly at the start of exercise, and that this stimulated ventilation via its effect on the peripheral chemoreceptors. Mills and Sampson $^{19}$ ) and Biscoe and Purves ${ }^{3)}$ have shown that excitation of the cervical sympathetic nerve causes an increase in ventilation through the sinus nerve. If this mechanism plays a dom. inant role in exercise under hypoxia, the simultaneous enhancements in ventilatory and heart rate responsiveness observed in the present study may well be explained. However, this sympathetic outflow mechanism was not confirmed by Eisel et al. ${ }^{91}$ in man.

Eldridge et al. ${ }^{8)}$ observed that electrical stimulation or injection of a GABA antagonist in hypothalamic locomotor region caused locomotion to develop, and this locomotion elicited an increase in respiration and arterial pressure in proportion to the level of locomotor activity; they suggested that a command signal emanating from the hypothalamus provides the primary drive for changes of respiration and circulation during exercise. Koepchen ${ }^{13)}$ also reported that a number of neural cells and networks in both the respiratory and cardiovascular centers converge and are interrelated with each other in the brain-stem reticular activating system.

In summary, we have observed closely correlated enhancement in ventilatory and heart rate responses during exercise with hypoxia. However, how and to what extent the peripheral chemoreceptors and the central neural mechanisms carry out their roles remains to be explored.

(Received, Mar. 12. 1987)

\section{Reference}

1) Asmussen, E. and Nielsen, M.(1975): Ventilatory response to $\mathrm{CO}_{2}$ during work at normal and at low oxygen tensions. Acta. Physiol. Scand., 39, 27-35.

2) Band, D. M., Linton, R. A. F., Kent, R. and Kurer, F. L. (1985): The effect of peripheral chemodenervation on the ventilatory response to potassium. Respir. Physiol., 60, 217-225.

3) Biscoe, T. J. and Purves, M. J. (1967) : Factors affecting the cat carotid chemoreceptor and cer- 
vical sympathetic activity with special reference to passive hind-limb movements. J. Physiol., 190, 425-441.

4) Comroe, H. H. Jr. and Schmidt, C. F. (1943): Reflexes from the limb as a factor in the hyper. pnea of muscular exercise. Am. J. Physiol., 138, 536-547.

5) Cunningham, D. J. C., Lloyd, B. B. and Patrick, J. M. (1963) : The relation between ventilation and end-tidal $\mathrm{PCO}_{2}$ inhalation. J. Physiol. (London), 169, 104-106.

6) Dixon, M. E., Stewart, B. B., Mills, F. C., Varvis, C. J. and Bates, D. V. (1961) : Respiratory consequences of passive body movement. J. Appl. Physiol. 16, 30-34.

7) Eldridge, F. L., Millhorn, D. E. and Waldrop, T. G. (1981) : Exercise hyperpnea and locomotion : parallel activation from the hypothalamus. Science, 211, 844-846.

8) Eldridge, F. L., Millhorn, D. E., Kiley, J. P. and Waldrop, T. G. (1985) : Stimulation by central command of locomotion, respiration and circulation during exercise. Respir. Physiol., 59, 313-337.

9) Eisel, J. H., Ritchie, B. C. and Severinghaus, J. W. (1967) : Effects of stellate ganglion blockade on the hyperpnea of exercise. J. Appl. Physiol., 22 (5), 966-969.

10) Honda, Y., Hasegawa, M. S., Hasegawa, T. and Severinghaus, J. W. (1979) : Decreased exercise hyperpnea in patients with bilateral carotid chemoreceptor resection. J. Appl. Physiol., 46(5), 908-912.

11) Kao, F. F., Schilig, B. B. and Brooks, C. (1955) : Regulation of respiration during induced muscular work in decerebrated dogs. J. Appl. Physiol., 7, 379-389.

12) Krogh, A. and Lindhard, J. (1913): The regulation of respiration and circulation during the initial stages of muscular work. J. Physiol., 47, 112-136.

13) Koepchen, H. P. (1983) : Respiratory and cardiovascular "Centers" : functional entirely or separate structures? In: Schläfke, M. E., see WR (eds), Central Neurone Enviroment. Springer.
Berlin, Heidelberg, New Yorks, Tokyo, pp. 221237.

14) Linton, R. A. F., Lim, M., Wolf, C. B., Wilmshurst, P. and Band, D. M. (1984): Arterial plasma potassium measured continuously during exercise in man. Clin. Sci., 67, 427-431.

15) Linton, R. A. F. and Band, D. M. (1985): The effect of potassium on carotid chemoreceptor activity and ventilation in the cat. Respir. Physiol., 59, 65-70.

16) LIoyd, B. B. and Cunningham, D. J. C. (1963) : A quantitative approach to the requlation of human respiration. In : Cunningham, D. J. C. and Lioyd, B. B. (eds), The regulation of human respiration. Blackwell Sci. Publ., Oxford, pp. 331-346.

17) Martin, B. J., Weil, J. V., Spark, K. E., McCullough, R. E. and Grover, R. F. (1978) : Exercise ventilation correlates positively with ventilatory chemoresponsiveness. J. Appl. Physiol., 45(4), 557-564.

18) MacCloskey, D. I. and Mitchell, J. H. (1972) : Reflex cardiovascular and respiratory responses originating in exercise muscle. J. Physiol. (London), 224, 173-186.

19) Mills, E. and Sampson, S. R. (1969) : Respiratory responses to electrical stimulation of the cervical sympathetic nerve in decerebrate, unanaesthe. tized cats. J. Physiol. (London), 202, 271-282.

20) Miyamoto, Y., Hiura, T., Tamura, T., Nakamura, T., Higuchi, J. and Mikami, T. (1982) : Dynamics of cardiac, respiratory, and metabolic function in men in response to step work load. J. Appl. Physiol., 52, 1198-1208.

21) Miyamura, M., Folgering, H. T. H., Binkhorst, R. A., Smolders, E. D. J. and Kreuzer, F. (1976) : Ventilatory response to $\mathrm{CO}_{2}$ at rest and during positive and negative work in normoxia and hyperoxia. Pflügers Arch., 364, 7-15.

22) Natalino, M. R., Z willich, C. W. and Weil, J. V. (1977) : Effects of hyperthermia on hypoxic ven. tilatory response in normal man. J. Lab. Clin. Med., 3, 564-572.

23) Ohyabu, Y., Yoshida, A., Hayashi, F., Nishibayashi, Y., Sakakibara, Y., Sato, N. and Honda, 
Y. (1984): Ventilatory and heart rate responses to hypoxia in well-trained judo athletes. Eur. J. Appl. Physiol., 52, 451-456.

24) Petersen, E. S. and Vejby-Christensen, H. (1977): Effects of body temperature on ventilatory response to hypoxia and breathing pattern in man. $42(4)$, 492-500.

25) Spode, R. and Schläfke, M. E. (1975) : Influence of muscular exercise on respiration after central and peripheral chemodenervation. 359, R 49.

26) Wasserman, K., Whipp, B. J. and Gastagna, J. (1974) : Cardiodyamic hyperpnea : hyperpnea se- condary to cardiac output increase. J. Appl. Physiol., 36(4), 457-464.

27) Wasserman, K.(1978) : Breathing during exercise. N. Engl. J. Med., 298, 780-785.

28) Weil, J. V., Byrne-Quinn, E., Sodal, I. E., Kline, J. S., McCullough, R. E. and Filley, G. F. (1972) : Augmentation of chemosensitivity during mild exercise in normal man. J. Appl. Physiol., 33(6), 813-819.

29) Yamamoto, W. S. (1960) : Mathematical analysis of the time course of alveolar $\mathrm{CO}_{2}$. J. Appl. Physiol., 15, 215-219. 